\title{
Potential Effects of Corrosion Damage on the Performance of Reinforced Concrete Member
}

\author{
Hamidun Mohd Noh ${ }^{1,2, a}$ and Yoshimi Sonoda ${ }^{1}$ \\ ${ }^{1}$ Department of Civil Engineering, Kyushu University, 744 Motooka, Nishi-ku, Fukuoka 819-0395, Japan \\ ${ }^{2}$ Faculty of Technology Management and Business, Universiti Tun Hussein Onn Malaysia, 86400 Parit Raja, Johor, \\ Malaysia
}

\begin{abstract}
Corrosion of steel in reinforced concrete is one of the most serious issues for the owners. The main consequences of this phenomenon include loss of cross section of steel area, induced the expansive pressure which caused cracking of concrete, spalling and delaminating of the concrete cover. Thus, it reduces the bond strength between steel reinforcing bar and concrete, and deteriorates the strength of whole structure. In this study, a non-linear finite element analysis was conducted to investigate the potential effects of corrosion damage. A series of corroded reinforced concrete cylinder is used in the parametric study to assess the influence of different level of corrosion to the structural performance. As a result, a clear picture of corrosive expansion was investigated and the relationship between the expansive pressure and the degree of corrosion was identified to be the important factors of the structural deterioration.
\end{abstract}

\section{Introduction}

Corrosion reinforcement is one of the main causes of structural deterioration and the most predominant degradation mechanisms in the reinforced concrete structures. It is usually associated with carbonation phenomenon or chlorides penetration, which generally induces uniform and localized, attacks respectively. Corrosion of steel in concrete causes internal damage to reinforced concrete elements, owing to the loss of steel area and the formation of associated expansive corrosion products.

The properties of oxide layers as the corrosion products have a great influence on corrosion crack in the concrete. The most influential factor is the expansion ratio of the oxide which depends on the specific type of oxide formed $[1,2]$. Depending on the level of oxidation, the volume increase due to rebar corrosion is commonly around $2.0[3,4]$ and would be up to 6.5 times than the original iron volume which get consumed by the corrosion process because of the formation of various corrosion products [5]. Nevertheless Molina [4] claimed that the effective expansion ratio maybe less than that corresponding to a given type if the oxide diffuse in the porous structure of the concrete.

When corrosion of reinforcement develops significantly, the corrosive products expand continuously and generate internal pressure to the concrete surface around the steel bar. The continuous process of reinforcement corrosion does not only affects in structural serviceability by

\footnotetext{
${ }^{a}$ Corresponding author : hamidun@doc.kyushu-u.ac.jp
} 
cracking, or even spalling the concrete cover, but also give serious impact on the structural safety by decreasing the load-bearing capacity. Besides, the physical effects of corrosion include loss of steel area, loss of bond strength between steel reinforcing bars and concrete, and reduce the concrete strength due to cracking.

In the present study, the potential effects of corrosion damage on the performance of reinforced concrete cylinder were investigated. The main effects of corrosion are recognized and considered in the analysis. A reinforced concrete cylinder with concrete diameter of $100 \mathrm{~mm}$ and $200 \mathrm{~mm}$ length was modelled consisting of $19 \mathrm{~mm}$ diameter of reinforcement bar. The detail dimension is shown in Figure 1.

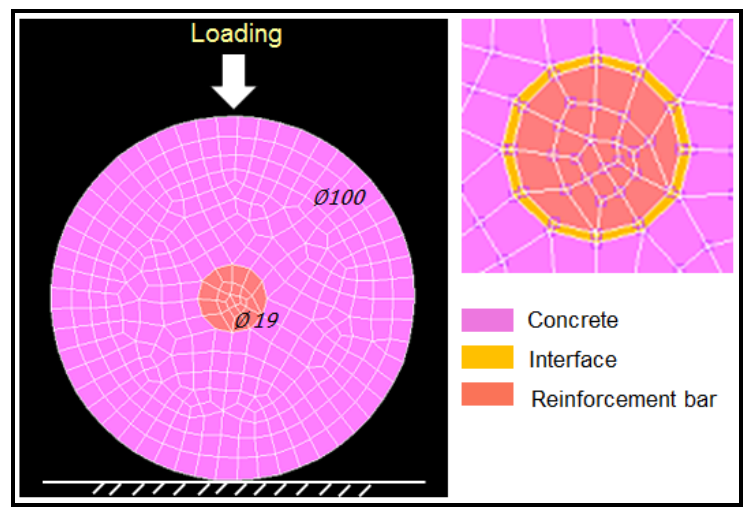

Figure 1. Beam cross-section and dimension.

\section{Numerical Simulation}

\subsection{Finite element modelling of beam specimen}

A three-dimensional finite element model is adopted in this study using the non-linear finite element code of MARC 2010. By using the 8 nodes of hexahedral elements, concrete and the main reinforcements was classified as solid. By considering the changes in the adhesion strength between the reinforcement bar and concrete, the interface element was applied by using 8 nodes hexahedral elements.

\subsection{Corrosion damage model}

Figure 2 shows the material properties of concrete and the bond-slip relationship. The rebar was assumed as complete elasto-plastic body and constitutive law based on the von Mises yield condition is adopted. As for the concrete, elastic-plastic constitutive law based on the Drucker-Prager yield condition is applied. The degradation ratio due to the corrosion is defined according to the degree of damage in three principal axis direction as $\varnothing_{\mathrm{x}}, \varnothing_{\mathrm{y}}$ and $\varnothing_{\mathrm{z}}$ by assuming the tension softening. To adequately assess the progress of cracks in the concrete, it is necessary to make the tension softening stress released by subsequent tensile strength. Then, only the extracted positive principal strain component, the degree of damage in principal strain direction $\mathrm{D}_{\mathrm{x}}^{\mathrm{L}}, \mathrm{D}^{\mathrm{L}} \mathrm{y}$ and $\mathrm{D}^{\mathrm{L}} \mathrm{z}$ are converted to the whole coordinate axes of $D^{G}, D^{G}$ and $D^{G}$. The degradation ratio of each coordinate axis direction was calculated by the following Equation (1).

$$
\varnothing_{x}=\sqrt{1-D_{x}^{G}},\left(D_{x}^{L}=\frac{\varepsilon_{x}^{L}}{\varepsilon_{u}}\right) ; \varnothing_{y}=\sqrt{1-D_{y}^{G}},\left(D_{y}^{L}=\frac{\varepsilon_{y}^{L}}{\varepsilon_{u}}\right) ; \varnothing_{z}=\sqrt{1-D_{z}^{G}},\left(D_{z}^{L}=\frac{\varepsilon_{z}^{L}}{\varepsilon_{u}}\right)
$$


Equation (1) shows the relationship between $\varnothing_{x}, \varnothing_{y}, \varnothing_{z}$ and $D^{G}{ }_{x}, D^{G}{ }_{y}, D^{G}$ with the definition of $\mathrm{D}^{\mathrm{L}}, \mathrm{D}_{\mathrm{y}}^{\mathrm{L}}, \mathrm{D}_{\mathrm{z}}^{\mathrm{L}}$. Here, $\varepsilon_{\mathrm{u}}$ is defined as tensile strain limit. In addition, the relationship between the stress rate and the degradation ratio associated with the tension softening is defined in Equation (2).

$$
\alpha_{x x}=\phi_{x}^{2}, \quad \alpha_{y y}=\phi_{y}^{2}, \quad \alpha_{z z}=\phi_{z}^{2}
$$

Furthermore, in this analysis the degradation ratio was multiplied by elastic stiffness matrix and anisotropic constitutive law with damage influence is obtained as shown in Equation (3).

$$
\left\{\sigma_{\mathrm{ij}}\right\}=\left\{\left[\mathrm{D}^{\mathrm{e}}\right]-\left[\mathrm{D}^{\mathrm{p}}\right]\right\}\left\{\varepsilon_{\mathrm{kl}}\right\}
$$

where $\mathrm{D}^{\mathrm{e}}$ is derived as following equation :

$$
\left[D^{e}\right]=\left[\begin{array}{cccccc}
\varphi_{x}^{2}(\lambda+2 \mu) & \varphi_{x} \varphi_{y} \lambda & \varphi_{x} \varphi_{z} \lambda & 0 & 0 & 0 \\
\varphi_{y} \varphi_{x} \lambda & \varphi_{y}^{2}(\lambda+2 \mu) & \varphi_{y} \varphi_{z} \lambda & 0 & 0 & 0 \\
\varphi_{z} \varphi_{x} \lambda & \varphi_{z} \varphi_{y} \lambda & \varphi_{z}^{2}(\lambda+2 \mu) & 0 & 0 & 0 \\
0 & 0 & 0 & \varphi_{x} \varphi_{y} 2 \mu & 0 & 0 \\
0 & 0 & 0 & 0 & \varphi_{y} \varphi_{z} 2 \mu & 0 \\
0 & 0 & 0 & 0 & 0 & \varphi_{z} \varphi_{x} 2 \mu
\end{array}\right]
$$

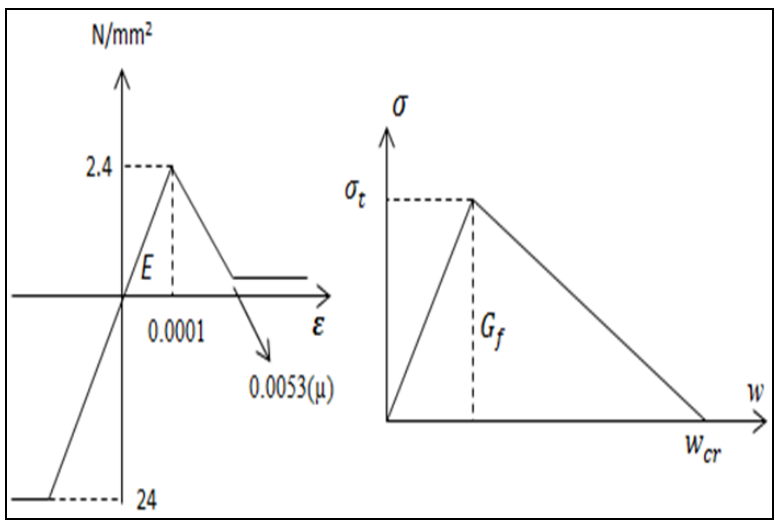

Figure 2. Material properties and bond-slip.

\section{Mechanism of Deformation Process Due To Steel Corrosion}

\subsection{Corrosion and expansion pressure}

The corrosion in concrete causes volume expansion of steel bar. Generally, the expansive pressure due to the volumetric change of the steel bar in concrete induces the tensile strains in the surrounding concrete and they are proportional to the degree of corrosion. As the expansion process begins continuously, the tensile strains developed and induces cracks in the surrounding concrete and also at the surface of concrete cover. In order to analyze the cracking of concrete cover due to steel corrosion, it is necessarily to know the relation between the amount of corrosion of steel bar and the internal pressure arises from the corrosion. Therefore, a realistic relation between the amount of corrosion and the internal expansion pressure can be investigated in this study. 


\subsection{Deformation of corrosion layer}

Kim [6] proposed a deformation model of steel bar corrosion. It was detailed out in Figure 3 which consist $r_{0}$ as the initial radius of steel bar and $x_{p}$ is the loss radius of steel bar due to corrosion. Meanwhile, the radius increment of steel bar due to corrosive expansion under restraint and unrestraint condition $(\mathrm{mm})$ represent by $\mathrm{U}_{\mathrm{r}}$ and $\Delta \mathrm{r}_{\mathrm{b}}$, respectively while the degree of corrosion of the steel bar which based on the ratio of weight loss due to corrosion to the initial weight of steel bar is known as $\mathrm{w}_{\text {corr }}$.

The corrosion product layer is compressed by the strain $\varepsilon_{\text {rust }}$ due to expansive pressure, $P$. Lundgren [7] derived the relationship between normal stress versus strain of rust evaluated from a combination of experimental results and analysis together with the chosen parameter $K_{\text {rust }}$ and $p$. According to their research, analysis results have a good agreement with the experimental results using the value of $K_{\text {rust }}=7.0 \mathrm{GPa}$ and $p=7.0$. Thus the expansive pressure $\mathrm{P}$ is defined in Equation (5) as follows:

$$
P=K_{\text {rust }}\left[\frac{u_{r}-r_{b}\left(\sqrt{1+\left(v_{r}-1\right) w_{\text {corr }}}-1\right)}{r_{b}\left[\left(1-\sqrt{1-w_{\text {corr }}}\right)+\left(\sqrt{1+\left(v_{r}-1\right) w_{\text {corr }}}-1\right)\right]}\right]
$$

\subsection{Mechanical behavior of the rust}

The mechanical behavior of the corrosion products needs to be known in modelling the corrosion layer. Molina [4] assume that the rust is elastic but the mechanical properties of the rust should be replaced by initial property of steel. Meanwhile, a scratching test was used by Petre-Lazar and Gerard [8] to explore the mechanical properties of the corrosion products. They conclude that rust is cohesion-less assemblage of incompressible crystals. Al-Sulaimani [9] and Cabrera and Ghoudoussi [10] have carried out pullout tests on corroded reinforcement bars concentrically placed in concrete blocks. In their study, the reinforcement corroded until the specimen was cracked and corrosion penetration was measured by the weight loss method. In addition, they performed axisymmetric finite element analyses of the test specimens and only the concrete was modelled with expansive normal stress. In this study, we also considered only the concrete domain with a constitutive model based on elastic-plastic theory.

Since the Young's modulus of steel is much larger than concrete, Lundgren [7] assumed that the deformation of the reinforcement bar is negligible. Furthermore, the stiffness of the bond layer is large enough so that the deformation of the bond layer is also negligible. Thereby, Lundgren [7] concluded that the deformation at the hole approximately equals to the deformation in the corrosion layer, $\mathrm{U}_{\mathrm{r}}$. Therefore, the value of $U_{r}$ can be calculated as the value of strain in the rust.

\section{Results and Analysis}

In general, cracks and rebar corrosion of the reinforced concrete structures are caused by various environment factors and reduction of adhesion strength is observed. In this study, the adhesion strength of rebar was also considered with reference to the research by Lee [11]. The relationship of the corrosion rate and the adhesion strength of the corroded reinforcing bars were stated in Equations (6) and (7).

$$
\begin{gathered}
\tau_{\max }=0.34 \sigma_{c}-1.93 \\
\tau_{\text {max }}=5.21 e^{-0.0561 \Delta w}
\end{gathered}
$$


Here, $\sigma_{c}$ is the compressive strength of the concrete and $\Delta w$ represents the corrosion rate of reinforcing steel (\%). Corrosion of the rebar was analyzed with respect to the 2 levels of degradation state which are $0 \%, 10 \%, 20 \%, 40 \%$ and $60 \%$. The bond strength for each corrosion rate are $6.23 \mathrm{MPa}$, 2.97MPa, 1.70MPa, 0.55 MPa and 0.18MPa, respectively.

\subsection{Volume expansion of rust in corroded concrete}

When a rebar starts to corrode, a gradual decrease of its diameter is produced. In this analysis, the gradual decrease of diameter, $x p$ is calculated at $0.4875 \mathrm{~mm}$. Together with the generation of rust, the increases in volume induce the formation of cracks when the concrete's tensile strength is surpassed. The cracks are generated first at the bar-concrete interface and then propagate radially.

As can be seen in Figure 3, it is presented the rust expansion of $19 \mathrm{~mm}$ diameter steel bar at $20 \%$ of corrosion degree. Under the unrestraint condition, $\Delta r_{b}$ at $\alpha$ value of 0.523 and 0.622 correspond to the free expansion of $1.6303 \mathrm{~mm}$ and $1.2544 \mathrm{~mm}$, respectively. Meanwhile, under restraint concrete condition, the value of $U_{r}$ at $\alpha$ value of 0.523 and 0.622 are $1.6209 \mathrm{~mm}$ and $1.2463 \mathrm{~mm}$, respectively.

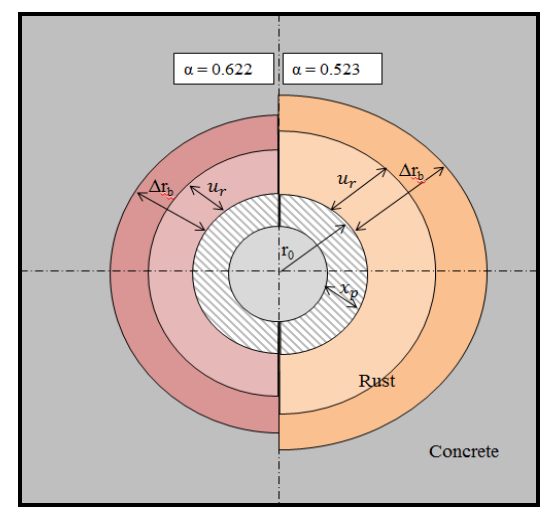

Figure 3. Expansion of rust in concrete.

\subsection{Expansive pressure in corroded concrete}

Once corrosion is induced in a structure, the expansive pressure will be generated which caused cracking to the concrete. As can be seen in Figure 4, the expansive pressure is increasing when the amount of corrosion increase.

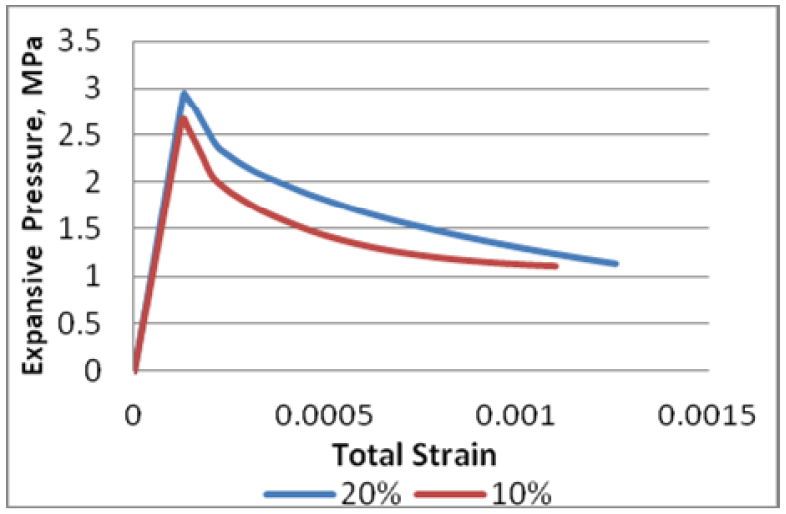

Figure 4. Expansive pressure relationship. 
Structure with $20 \%$ corrosion generates higher expansive pressure with $2.94 \mathrm{MPa}$. Meanwhile, the pressure value drop until $2.62 \mathrm{MPa}$ on the $10 \%$ corrosion curve. The distribution of strain at the cross section of the beam is presented in Figure 5. Since the corroded areas consist of the reinforcement only, the strain distribution is concentrated at the bar-concrete area as the stress level is increasing when the corrosion degree increase.

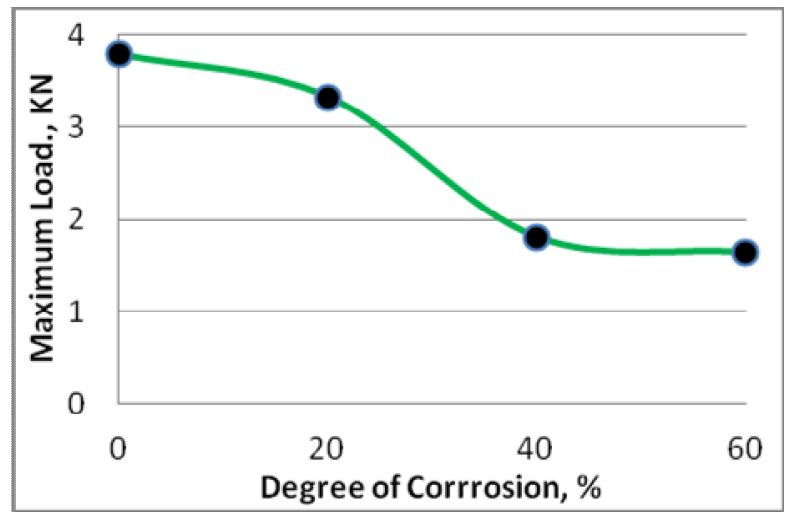

Figure 5. Structural strength reduction.

\subsection{Structural strength reduction due to rebar corrosion}

Further analysis was conducted to investigate the influence of corrosion to the structural strength. The corrosion is considered along the reinforcement bar in the concrete cylinder. Figure 6 presents the relationship between load bearing capacity and the degree of corrosion of the concrete cylinder. It was shown that $0 \%$ corrosion have the higher bearing force with $3.79 \mathrm{kN}$. Meanwhile, the value of the bearing force for corrosion degree of $20 \%$ dropped slightly to $3.33 \mathrm{kN}$. Then, the gradient of the graph change drastically to the $40 \%$ corrosion degree with bearing capacity of $1.81 \mathrm{kN}$ before decrease to $1.64 \mathrm{kN}$ at $60 \%$ degree of corrosion. The results illustrate that the corroded structure generates expansive pressure and caused cracking to the concrete surface. After reach the maximum bending capacity, the structure get off as the corrosion cause severe condition since the stiffness decrease due to corrosion and caused noticeable strength reduction as shown in Figure 7.

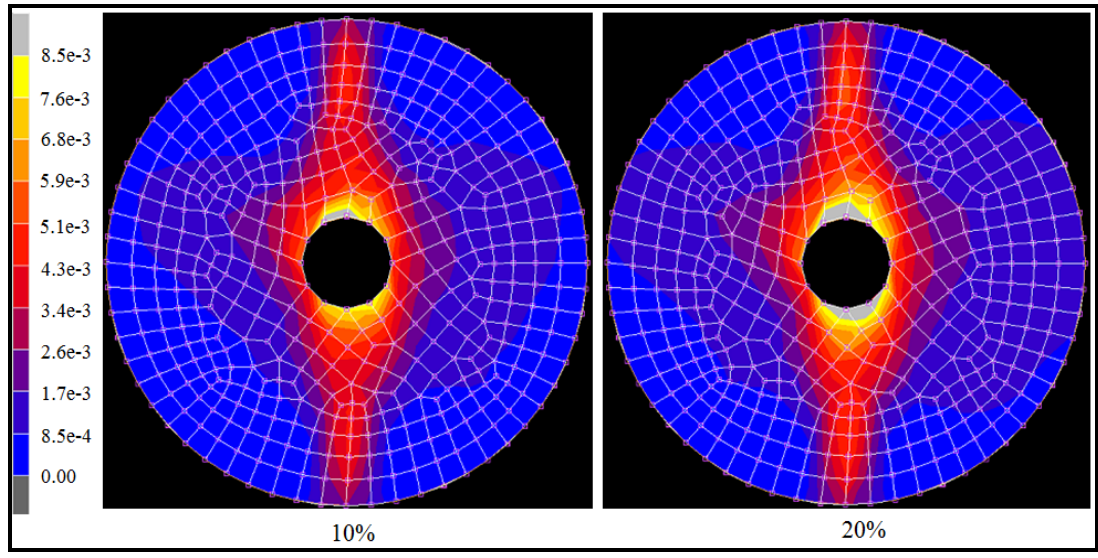

Figure 6. Strain distribution. 


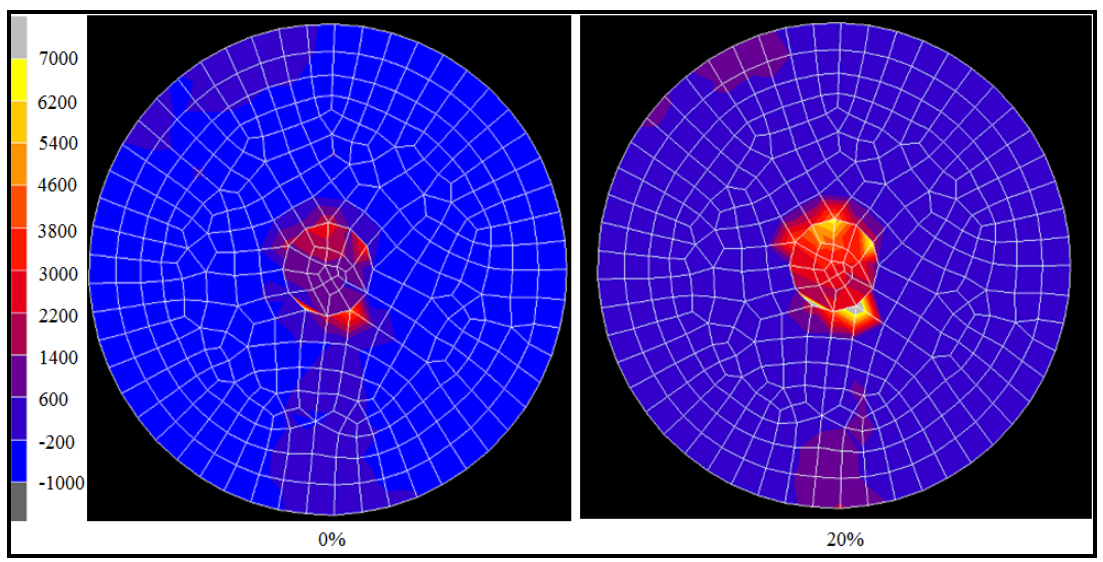

Figure 7. Stress distribution.

\section{Conclusions}

In this study, we could predict the residual strength of reinforced concrete cylinder under the corrosion condition using the finite element analysis. However, the quantitative relation between the degree of corrosion and its influence on the mechanical properties are still needed to investigate. Thus, we are going to do the experimental validation in the next stage.

\section{References}

[1] K. Tutti, Corrosion of steel in concrete. Report No. 4 of Swedish Cement and Concrete Research Institute, Stockholm, Sweden, (1982).

[2] P.K. Mehta and P.J.M. Monteiro, Concrete Microstructure, Properties and Materials, Indian Concrete Institute, Chennai, India (1997).

[3] C. Andrade, C. Alonso and F.J. Molina, Cover cracking as a function of rebar corrosion: Part Iexperimental test, Mater. Struct., 26, 453-464, (1993).

[4] F.J. Molina, C. Alonso and C. Andrade, Cover cracking as a function of rebar corrosion: part IInumerical model, Mater. Struct., 26, 532-548, (1993).

[5] K. Bhargava, A.K. Ghosh, Y. Mori and S. Ramanujam, Model for cover cracking due to rebar corrosion in RC structures, Eng. Struct., 28, 1093-1109, (2006).

[6] K.H. Kim, S.Y. Jang, B.S. Jang and B.H. Oh, Modeling mechanical behavior of reinforced concrete due to corrosion of steel bar, ACI Material J., 107(14), 106-113, (2010).

[7] K. Lundgren, Bond between corroded reinforcement and concrete, Technical Report, Chalmers University of Technology, Göteborg, Sweden, (2001).

[8] I. Pètre Lazar and B. Gerard, Mechanical behaviour of corrosion products formed at the steel concrete interface: Testing and modelling, Conditions Monitoring of Materials and Structures, Proc. of 14th Engineering Mechanics Conf., United States, (2000).

[9] Al-Sulaimani, G.J. Kaleemullah, M. Basunbul and I.A. Rasheeduzzafar, Influence of corrosion and cracking on bond behaviour and strength of reinforced concrete members, ACI Struct. J., 87 (2), 220-231,(1990).

[10]J.G. Cabrera and P. Ghoddoussi, The effect of reinforcement corrosion on the strength of the steel-concrete bond, Bond in Concrete, Proc. of Int. Conf. CEB, Riga, (1992).

[11]H.S. Lee, T. Noguchi and F. Tomosawa, Evaluation of the bond properties between concrete and reinforcement as a function of the degree of reinforcement corrosion, Cement and Concrete Research, 32(8), 1313-1318, (2002). 